\title{
Fractions of traditionally brewed rice beverage relieve anxiety and improve spatial memory in mice
}

\author{
Bhuwan Bhaskar ${ }^{1}$ (D), Atanu Adak ${ }^{1}$ (D) and Mojibur R. Khan ${ }^{1 *}$ (D)
}

\begin{abstract}
Rice beverages are traditionally prepared and consumed popularly by the different ethnic groups of North East India and claimed to have several health benefits. In an attempt to validate the traditional claims, effects of different fractions of the beverage were studied using mouse model. To investigate its effects on behavior, mice were treated with different fractions of rice beverage that included the beverage as a whole, insoluble and soluble fractions. Intragastric treatments of these fractions were given to the mice ( $n=6$ per group) for 30 days, and behavioral studies were performed on elevated plus and $Y$ maze to evaluate anxiety and spatial memory, respectively. Next-generation sequencing of metagenomic DNA of the beverage indicated the presence of 157 OTUs, and 26 bacterial genera were dominant with an abundance of $0.1 \%$. The insoluble fraction and the whole beverage treatments reduced the anxiety-like symptoms in animals indicating the probable role of microbes. Spatial memory improved in all the treatments compared to the control, of which the rice beverage treatment showed the highest levels $(p<0.05)$. Gas chromatography and mass spectroscopy-based metabolite profiling of the beverage revealed 10 alcohols, 29 sachharides, 43 acids, and 13 amino acids. Findings of this study suggest a positive effect of rice beverage on anxiety and spatial memory of mice, justifying the claims by ethnic communities on its role on mood regulation.
\end{abstract}

Keywords: Anxiety, Behavior, Fermented beverage, Microbial diversity, Spatial memory

\section{Introduction}

North East India consists of eight states, namely Arunachal Pradesh, Assam, Manipur, Meghalaya, Mizoram, Nagaland, Sikkim, and Tripura (Fig. 1) and physiographically categorized into the Eastern Himalayas, Northeast Hills (Patkai-Naga Hills and Lushai Hills), and the Brahmaputra and Barak Valleys. The region is home to around 225 tribes which makes it rich in diverse ethnicity culture and food practices [1]. The foods prepared and consumed by these communities have a strong connection with their sociocultural, spiritual life, and health. These foods include different types of fermented foods

*Correspondence: mojibur.khan@gmail.com

${ }^{1}$ Molecular Biology and Microbial Biotechnology Laboratory, Institute of Advanced Study in Science and Technolgy, Vigyan Path, Paschim Boragaon, Guwahati, India

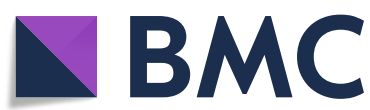

and beverages. The rich ethnic diversity and surplus availability of bioresources contribute to a huge reserve of artisanal foods and beverages in this region which are often commercially available in small regional markets. Most of the ethnic communities of this zone prepare and consume fermented foods and beverages; however, the name, recipe, and preparation method often varies from tribe to tribe. Since rice is the major staple food of the region, a wide variety of rice-based fermented alcoholic beverages are popularly consumed. Each tribe has a recipe for the preparation of the starter, which serves as the source of microbial inoculam, and also, the beverage has a different vernacular name based on the tribe. Though the overall process remains the same for each tribe, the differences lie in the compostion of starter, variety of rice to be used for fermentation, and some additional steps during filtration of the final product. The starter serves

(c) The Author(s). 2021 Open Access This article is licensed under a Creative Commons Attribution 4.0 International License, which permits use, sharing, adaptation, distribution and reproduction in any medium or format, as long as you give appropriate credit to the original author(s) and the source, provide a link to the Creative Commons licence, and indicate if changes were made. The images or other third party material in this article are included in the article's Creative Commons licence, unless indicated otherwise in a credit line to the material. If material is not included in the article's Creative Commons licence and your intended use is not permitted by statutory regulation or exceeds the permitted use, you will need to obtain permission directly from the copyright holder. To view a copy of this licence, visit http://creativecommons.org/licenses/by/4.0/. The Creative Commons Public Domain Dedication waiver (http://creativecommons.org/publicdomain/zero/1.0/) applies to the data made available in this article, unless otherwise stated in a credit line to the data. 


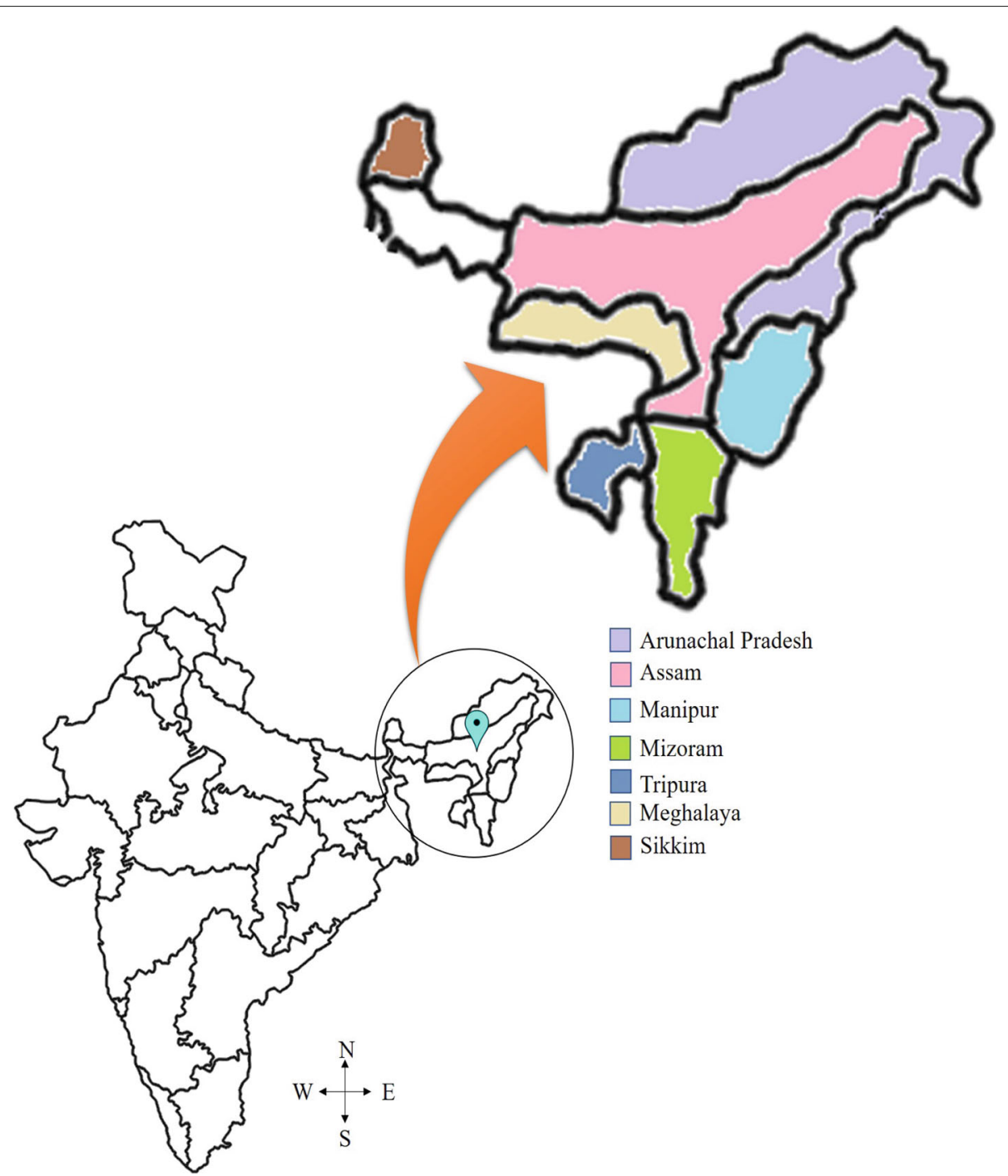

Fig. 1 The seven states of North East India are inhabited by many indigenous communities having diverse food habits. Majority of these communities consume fermented foods and beverages. Assam is a state in this region with a rich diversity of rice-based fermented beverages. The beverage holds an intrinsic value in the sociocultural life of these communities (map adapted from https://www.pikpng.com)

as inoculum consisting of starch-degrading and alcoholproducing microbes along with lactic acid bacteria. It has been reported to contain the bacteria Lactobacillus plantarum, Lactobacillus brevis , Leuconostoc lactis, Weissella cibaria, Lactococcus lactis, Weissella para mesenteroides, and Leuconostoc pseudomesenteroideetc [2]. The starter is mixed with cooked rice under hygienic conditions for fermentation, and the liquid is separated from the mass by decantation and filtration [3]. Consumption of rice beverage is traditionally believed to exert health benefits pertaining to improved digestive, excretory, and endocrine functions and relieves stress [3]. The beverage has been reported to be rich in essential nutrients such as carbohydrates, amino acids, and organic acids along with other aromatic compounds [4]. The carbohydrates serve as energy source and also add to the overall taste of the beverage. Also, they exert prebiotic and neuromdulatory effects by regulating the gut microbiota [5]. The presence of amino acids in abundance is also an indication of lowmolecular-weight peptides in the beverage which could attribute to its antioxidant and antimicrobial properties $[6,7]$. Additionally, they also contribute to the organoleptic properties of the beverage pertaining to taste, aroma, etc. [8]. Beyond basic nutrition, the amino acids in the beverage also confer additional health benefits. For example, glutamatic acid acts as precursor for important neurotransmitters thereby affecting the mental health [9]. Beta alanine is yet another amino acid having antioxidant, immune-enhancing, and anti-aging properties, and also, it has been reported to demonstrate anxiolytic effects, 
in human, rat, and mouse models [10-12]. A growing body of evidence indicates the roles of fermented foods in the brain and cognitive health promotion [13, 14]. These effects arise due to the synergistic effect of the microbes, their metabolites, and the nutrients in these foods [15]. A recent study in mice has reported the effect of fermented beverage Kefir in reducing stress and repetitive behavior by positively modulating the microbiota-gut-brain axis [16]. Similarly, another study revealed the effect of red wine in improving the spatial memory and fear memory in mice [17].
Considering the health benefits of fermented foods and the nutritional content of the traditionally brewed rice beverage, we hypothesize that the overall nutrients and microbes in the beverage may improve the brain function. Therefore, this study aimed to explore the effects of rice beverage and its fractions on anxiety and spatial memory, using mouse model in an attempt to validate the claims by ethnic communities (Fig. 2). To the best of our knowledge, this is the first study on the effect of traditionally brewed rice beverage on the anxiety and spatial memory in mice.

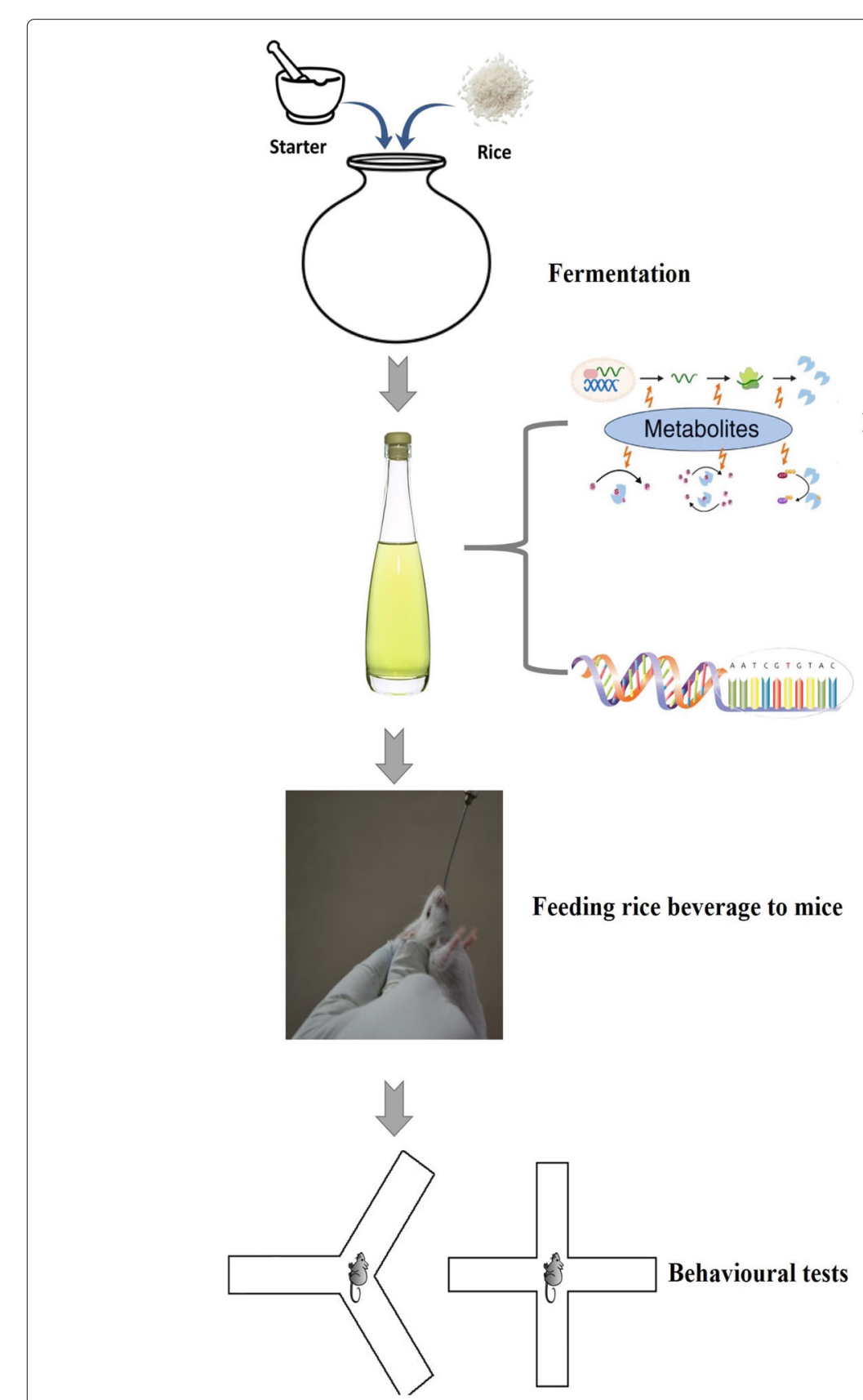

Fig. 2 Summery of the experimental process performed in the study 


\section{Methods}

\section{Rice fermentation}

Rice beverage was prepared based on the traditional knowledge of Tiwa community of Assam. The starter cake was prepared using different plants and rice as described in our earlier patent [18]. Further, $1 \mathrm{~kg}$ of rice (Oryza sativa) was boiled and allowed to cool down to room temperature. A $30 \mathrm{~g}$ of starter cake, crushed into powder, was mixed with the cooled rice and kept for solid state fermentation for 8 days at $30{ }^{\circ} \mathrm{C}$. After fermentation, the mass was sieved with a muslin fabric to obtain rice beverage (RB) which was further centrifuged at $5000 \mathrm{rpm}$ for $5 \mathrm{~min}$ to separate the supernatant containing the soluble fraction (SF), and the pellet was resuspended in sterile water up to the initial volume, denoted as insoluble fraction (IF).

\section{Biochemical analyses and non targeted profiling of rice beverage metabolites by gas chromatography-mass spectrometry (GC-MS)}

The $\mathrm{pH}$ was measured in a digital $\mathrm{pH}$ meter ( $\mathrm{pH} 510$, Orion Star A111). The alcoholic fraction was evaporated and collected in a rotary evaporator to estimate the alcohol by volume using potassium dichromate reagent [19]. Reducing sugars, antioxidant activity, and total phenolic content was determined as described elsewhere [20-22]. GC-MS was carried out as per protocol descibed by Das et al. [4]. Briefly, the methanolic extract of the beverage was concentrated under vacuum and derivatized using $N$ methyl- $N$-(trimethylsilyl) trifluoroacetamide (MSTFA). GC-MS analysis was carried out in a Shimadzu GC 2010 Plus-triple Quadrupole. The peaks were identified using the National Institute of Standards and Technology (NIST) library, USA, and the column bleeds were removed prior to analyses.

\section{Next-generation sequencing (NGS) of metagenomic DNA extracted from rice beverage}

Metagenomic DNA from rice beverage was extracted following protocol described by Das et. al [23]. The DNA was subjected to NGS with sequencing service provider Macrogen Inc. (Seoul, Republic of Korea). The V3-V4 region of bacterial $16 \mathrm{~S}$ rDNA was amplified using 341F$805 \mathrm{R}$ primers. The NGS library was prepared using the Nextera XT library preparation kit following the Illumina MiSeq protocol (Illumina Inc., 2017). Sequencing was carried out in an Illumina MiSeq machine (MiSEq 2500) following $2 \times 300$ bp paired-end chemistry with the multiplexed pooled samples. The trimmed sequences were checked for FASTQ, and the high-quality regions with an average Phred score higher than 20 were considered for further analysis using QIIME (Quantitative Insights Into Microbial Ecology) pipeline. Each sequence was assigned taxonomy at phylum, class, order, family, and genus levels with $97 \%$ homology.

\section{Animals and experimental design}

Five-week-old (36 \pm 6 g) male Swiss albino mice $(n=6$ per group) were used for the study. Animals were housed in polypropylene cages (Tarsons, India), each cage containing 3 mice. They were fed ad libitum standard rodent pellet diet and water. Animals were divided randomly, based on treatments. A $7 \mu \mathrm{l} / \mathrm{g}$ body weight of RB, IF, and SF was administered whereas the controls $(\mathrm{CT})$ received sterile water using gavage. The dosage was equivalent to the reported human intake of the beverage based on their body weight to make a consistent gavage volume. All experiments were conducted following the guidelines of the Committee for the Purpose of Control And Supervision of Experiments on Animals (CPCSEA), Ministry of Environment, Forest and Climate Change, Government of India, New Delhi, and approved by the institutional animal ethical committee (approval no. IASST/IAEC/201617/07).

\section{Behavioral analyses}

After 30 days of treatment, elevated plus (EP) and Y maze tests were conducted following standard procedures to study anxiety and spatial memory, respectively, using the methods described earlier [24, 25]. The tests were conducted in an isolated room by placing the mouse in the mazes. An infrared camera (D3D, UK) was mounted parallel to the mazes to track the animal's movement. The mazes were made up of acrylic material, matte black in color, and cleaned with non-abrasive paper towels using $70 \%$ ethanol before and after each test. Animals were acclimatized prior to the start of the study.

\section{EP maze test}

The EP maze consisted of four arms, $30 \mathrm{~cm}$ long and $5 \mathrm{~cm}$ wide and was elevated $50 \mathrm{~cm}$ above the floor. One pair of opposing arms was exposed with a 3-cm-high parameter border along the outer edges while the other pair was enclosed with opaque walls of $12 \mathrm{~cm}$ high . The animal was allowed to explore the maze freely for $300 \mathrm{~s}$, and the process was recorded. Out of $300 \mathrm{~s}$, the time spent in the open arm was calculated as a measure of anxiolysis [26].

\section{Y maze test}

Th Y maze consisted of three arms of equal lengths of $38 \mathrm{~cm}$ separated from each other by $120^{\circ}$ and designated as $\mathrm{A}, \mathrm{B}$, and $\mathrm{C}$ for scoring. They were habituated to explore the mazes for $10 \mathrm{~min}$ having access to two arms. During the test run, a mouse was placed at the center of the maze and allowed to move freely through the maze during a 5-min session. Entry of the hind limb into an arm of the Y maze was considered for the scoring. Spontaneous alternation (SA), defined as the tendency of the animal to explore new arms, was calculated as a measure of spatial memory [27]. 


\section{Statistical analyses}

Behavioral parameters on the EP and $\mathrm{Y}$ maze across the groups were measured, and one-way ANOVA was performed using SigmaPlot to determine the differences among the treatment groups. Statistical significance was considered at $(p<0.05)$.

\section{Results and discussion}

The biochemical properties of the beverage (Table 1) are in line with the previous reports[4]. Out of 13 amino acids detected by GC-MS (Table 2), methionine, phenylalanine, threonine, and valine fell into the category of essential amino acids. This is a good indication in terms of the nutritional content of the beverage. Moreover, the complex L-Val-L-Leu has been reported to promote healthy gut bacteria [28]. Next, beta alanine has been effective in reducing anxiety and increasing BDNF expression in rats. Similarly, phenylalanine and glutamic acid are also reported to have neuromodulatory effects $[29,30]$. Other components, viz. cinnamic acid and threonic acid, have also shown memory-enhancing activities [31]. Further, sugars like allose and trehalose exert neuroprotective activities [32, 33].

From the NGS data, 574,030 quality reads showed a significant homology with predicted rRNA sequences in the Greengene database. A total of 157 OTUs were observed of which Bacillus was the most abundant genus (42.5\%) (Fig. 3). Similar to our findings, Bacillus has been found to be the most dominant genus in Chinese rice wine and plays important roles like development of flavor, production of important metabolic products, and synthesis of organic acids [34]. Next, an unclassified genus from Enterobacteriaceae was dominant, which is also present commonly in wines and other fermented beverages and exert antimicrobial activity by producing bacteriocins [35]. Next, the dominant taxa belonging to Leuconostocaceae produces lactic acid from carbohydrate fermentation and confers probiotic attributes. Moreover, Lactococcus and Lactobacillus have also been reported to exert such activities.

In the EP maze, more time spent in the open arms reflects less anxiety. IF treatmet spent the longest duration (162.55 s) in the open arm of the EP maze followed by RB

Table 1 Biochemical parameters of the rice beverage

\begin{tabular}{ll}
\hline Parameter & Inferences $^{*}$ \\
\hline $\mathrm{pH}$ & $3.98 \pm 0.005$ \\
Alcohol by volume $(\% \mathrm{v} / \mathrm{v})$ & $10.55 \pm 0.07$ \\
Reducing sugars $(\mathrm{mg} / \mathrm{ml})$ & $3.86 \pm 0.33$ \\
Percent inhibition of DPPH free radicals & $29.80 \pm 0.21$ \\
Antioxidant activity (ascorbic acid, $\mathrm{mg} / \mathrm{ml})$ & $1.22 \pm 0.12$ \\
Total phenolic content (gallic acid equivalent, $\mathrm{mg} / \mathrm{ml})$ & $0.392 \pm 0.01$ \\
\hline
\end{tabular}

${ }^{*}$ Mean of 3 replicates \pm standard error
(160.3 s) and SF (87.65 s) treatments. Significant differences were observed in the RB and IF groups compared to the SF group $(p<0.05)$ (Fig. 4). A higher SA \% in the $\mathrm{Y}$ maze reflects augmented spatial memory. RB showed the highest SA \% (74.56\%), followed by IF (73.65\%) and SF $(62.75 \%)$. The spatial memory was improved significantly $(p<0.05)$ in all treated groups with respect to the CT group (Fig. 5).

In the present study, the IF was devoid of alcohol and consisted of microbes and nutrients present in the fermented residues whereas the SF was devoid of microbes, but sugars and other dissolved constituents were present. The rice beverage, in contrary, was a combination of these two fractions. The presence of prebiotic and prebiotic components in the beverage is an indicative of "synbiotic" effects, wherein an array of health beneficial properties could be attributed which could include regulation of mental well being. In the EP maze, the RB and IF fractions showed differences with the SF. Interestingly, a synergistic effect was displayed in the $\mathrm{Y}$ maze due to the combined effects of different fractions. Spatial memory improved in all the treatments due to combined effect of the components.

The bidirectional interaction between the central nervous system and the enteric nervous system, known as the gut-brain axis, exhibits the communication between emotional and cognitive centers of the brain with the gastrointestinal tract [36]. Notably, this communication between the gut and the brain is regulated via the microbes by several pathways including the immune system, the vagus nerve, or by modulation of neuroactive compounds by the microbiota. Therefore, the microbes are considered to be key regulators of this communication, thereby regulating the mental well-being by the pshycobiotic activity. With extensive research on GBA, the role of microbiota in the regulation of the brain, behavior, and cognition is becoming clearer [37].

Bacillus, the most dominant genus observed in this beverage, have been known to exert multiple health benefits and probiotic attributes due to their tolerance and survivability under hostile environment of the gastrointestinal tract [38]. With this, they have been utilized in several fermented foods for their functional properties [39]. In line with our findings, this genus has been reported to enhance the mood by affecting the gut-brain axis [40]. Other bacteria like Enterobacteriaceae, Leuconostoc, Staphylococcus, Lactococcus, and Lactobacillus have been reported in different fermented foods with health benefits [41]. Furthermore, Leuconostoc is another probiotic bacterium which has been reported to demonstrate neuroprotective activity by improving the brain-derived neurotropic factor (BDNF) [42]. Furthermore, several species of Lactobacillus, Lactococcus, and Streptococcus have been extensively studied for their probiotic and brain modulatory effects. 
Table 2 List of metabolites obtained by GC-MS of the rice beverage

\begin{tabular}{|c|c|c|c|}
\hline Amino acids & Acids & Alcohols & Sugars \\
\hline Beta-alanine & (Acridin-9-ylamino)-acetic acid & 1-Monolinoleoylglycerol & 2-Deoxy-galactopyranose \\
\hline DL-ornithine & 1,2,3-Propanetricarboxylic acid & 4-Hydroxyphenylethanol & 3-Alpha-mannobiose \\
\hline Glutamic acid & 1,2-Benzenedicarboxylic acid & D-mannitol & Beta-D-(+)-talopyranose \\
\hline Glycine & 1,4-Benzenedicarboxylic acid & Dulcitol & Beta-DL-lyxopyranose \\
\hline L-aspartic acid & 2,5-Dimethoxycinnamic acid & Galactinol & Beta-gentiobiose \\
\hline L-glutamic acid & 2-Butenedioic acid & Glucitol & D-(-)-erythrose \\
\hline L-methionine & 2-Hydroxypropane-1,2,3-tricarboxylic acid & L-threitol & D-(-)-lyxofuranose \\
\hline L-phenylalanine & 2-Isopropyl-3-butyric acid & Myo-Inositol & D-(-)-lyxose \\
\hline L-proline & 2-Keto-I-gluconic acid & Pentitol & D-(-)-ribofuranose \\
\hline L-threonine & 3,4-Dihydroxymandelic acid & Xylitol & D-(-)-ribose \\
\hline L-valine & 3,4-Dimethylbenzoic acid & & D-(+)-cellobiose \\
\hline L-Val-L-leu & 3,5-Dimethoxycinnamic acid & & D-(+)-trehalose \\
\hline \multirow[t]{29}{*}{ Serine } & 5-(3,4-Dimethoxyphenyl) pentanoic acid & & D-allose \\
\hline & 5-Pyrimidinecarboxylic acid & & D-fructose \\
\hline & 9,12,15-Octadecatrienoic acid & & D-galactose \\
\hline & Acetic acid & & D-glucopyranose \\
\hline & Benzeneacetic acid & & D-glucose \\
\hline & Benzenepropanoic acid & & D-psicose \\
\hline & Benzoic acid & & D-ribopyranose \\
\hline & Butanedioic acid & & Fructose oxime \\
\hline & Butanoic acid & & Galactose oxime \\
\hline & Carbamic acid & & Gulose \\
\hline & Cyclopentanecarboxylic acid & & L-(-)-fucose \\
\hline & D- (+)-Glucuronic acid & & L-(-)-sorbose \\
\hline & Decanoic acid & & Lactulose \\
\hline & D-gluconic acid & & Maltose \\
\hline & Dodecanoic acid & & Melibiose \\
\hline & Ethanedioic acid & & Talose \\
\hline & Ethyl phosphoric acid & & \\
\hline & Glucaric acid & & \\
\hline & Heptadecanoic acid & & \\
\hline & Hexadecanoic acid & & \\
\hline & Hexanedioic acid & & \\
\hline & Idonic acid & & \\
\hline & L-threonic acid & & \\
\hline & Pantothenic acid & & \\
\hline & Pentanedioic acid & & \\
\hline & Phosphoric acid & & \\
\hline & Propanoic acid & & \\
\hline & Tetradecanoic acid & & \\
\hline & Trans-2,4-Dimethoxycinnamic acid & & \\
\hline
\end{tabular}

Prebiotic components are yet another trait to curb the neurological complications [43]. The inclusion of prebiotics and probiotics have been known to palliate psychiatric disorders like panic disorder, generalized anxiety disorder, major depression, and impaired brain function due to IBS [44]. The dietary components (prebiotics and probiotics) that influence the brain and behavior are defined as psychobiotics which modulate the gut-brain 


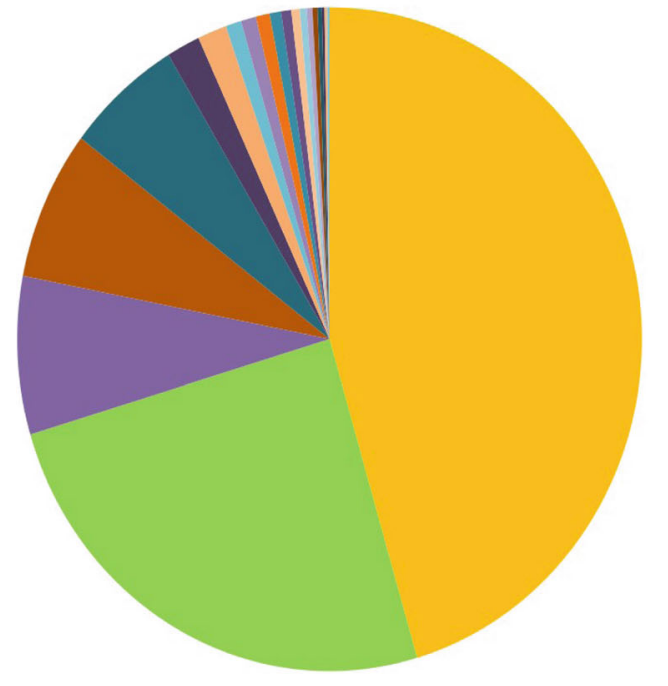
Bacillus
Enterobacteriaceae (unknown genus)
- Leuconostocaceae (unknown genus)
- Klebsiella
- Acinetobacter
- Lactococcus
Bacillaceae (unknown genus)
Acetobacteraceae (unknown genus)
Moraxellaceae (unknown genus)
- Staphylococcus
Enterobacteriaceae
- Leuconostoc
Lactobacillus
- Planococcaceae (unknown genus)
Bacillales (unknown genus)
- Streptococcus
- Proteus

\section{- Bacillaceae(unknown genus) \\ Enterococcaceae (unknown genus)}
Citrobacter

Fig. 3 Bacterial diversity of the traditionally fermented rice beverage, based on 16s rDNA sequences. A total of 157 bacterial genera were detected, of which, 20 were present in a relative abundance of at least $0.1 \%$

axis [45]. Moreover, polyphenols and their derivatives in wines have been known to positively affect the stressinduced neuronal response and in reducing anxiety. Additionally, these metabolites also affect the gut microbiota leading to healthy host physiology [46]. As diet remains a major factor to influence the brain and behavior, inclusion of psychobiotic elements can be effective for the prevention and treatment of certain neurological diseases [47].
Altogether, it is clearly evident that the components of the beverage affect the behavior and cognition that provides a clue of interference with the gut-brain axis. However, further research is required for subsequent validations considering several parameters such as dose and persistence of such effects. These studies would provide novel insights for the therapeutic potential of rice beverage for neurological complications.

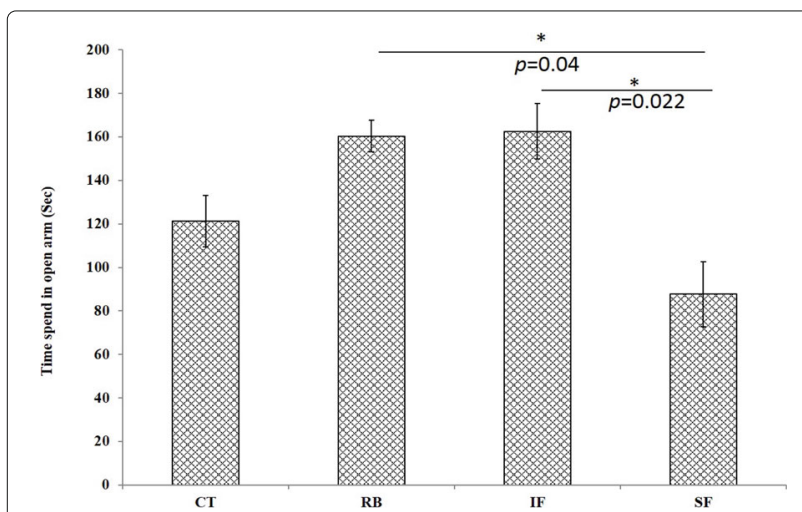

Fig. 4 Effects of different rice beverage fractions on behavioral parameters of mice as observed in the EP maze. During a 300 s test, the time spent on the open arm of the maze (expressed as mean \pm SEM) denotes less anxiety like behavior in the animals. Significant difference $\left({ }^{*} p<0.05\right)$

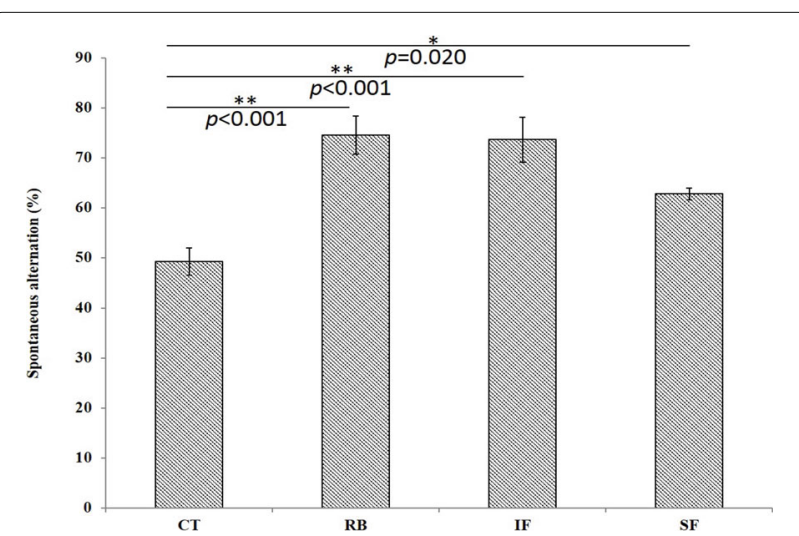

Fig. 5 Spontaneous alternation (\%) as calculated by scoring the entries into the new arms of the $Y$ maze. The animal's ability to explore new arms of the maze is related to an improved spatial memory. Significant difference $\left({ }^{*} p<0.05,{ }^{* *} p<0.05\right.$ ) 


\section{Conclusion}

Emergent research on the functional properties of fermented foods has led to global surge in their consumption, mainly due to the associated health benefits. There are certain fermented foods which are prepared by different ethnic communities as a culinary practice and remain away from commercial markets despite having health modulatory effects. These foods have a long history of consumption and are strongly associated with culture and tradition and often used as traditional medicine. Moreover, there is a lack of scientific justification of many such claims. Administration of rice beverage fractions showed improved brain functions in mice. These observations were due to a synergistic effect of nutritional components including prebiotics as well as microbes. Whether these results could be considered for the neuromodulatory effects of the beverage, further studies could target on its utilization as a functional food-based therapeutic interventions.

\section{Abbreviations}

ANOVA: Analysis of variance; DPPH: 2,2-Diphenyl-1-picrylhydrazyl; EP: Elevated plus; GBA: Gut-brain axis; GC-MS: Gas chromatography-mass spectrometry; MSTFA: N-methyl-N-(trimethylsilyl) trifluoroacetamide; NIST: National Institute of Standards and Technology; NGS: Next-generation sequencing; OTU: Operational taxonomic unit; QIIME: Quantitative Insights Into Microbial Ecology; SA: Spontaneous slternation; SCFA: Short-chain fatty acids

\section{Acknowledgements \\ This study was supported by the core fund of the Institute of Advance Study in Science and Technology (IASST), Department of Biotechnology (DBT, Government of India)-funded unit of excellence project (BT/550/NE/U-EXCEL/2014) and the Department of Science and Technology-funded ST/SC community development program in IASST (SEED/TITE/2019/103). The research was carried out in the Institutional Level Biotech Hub of IASST. The authors are thankful to Mrs. Anima Baishya for sharing traditional knowledge on rice beverage preparation.and to Mr. Milan Jyoti Das, Mr. Gwhwm Basumatary, and Mr. Abinash Nath for the assistance in the animal rearing and handling.}

\section{Authors' contributions}

$B B, A A$, and MRK designed the experiments. $B B$ and $A A$ performed the experiments. The manuscript was drafted by BB and revised by MRK. All authors read and approved the final manuscript.

\section{Funding}

This study was supported by the core fund of IASST and the Department of Biotechnology (DBT, Government of India)-funded unit of excellence project (BT/550/NE/U-EXCEL/2014).

\section{Declarations}

\section{Ethics approval and consent to participate}

All experiments were conducted following the guidelines of the Committee for the Purpose of Control And Supervision of Experiments on Animals (CPCSEA), Ministry of Environment, Forest and Climate Change, Government of India, New Delhi, and approved by the institutional animal ethical committee (approval no. IASST/IAEC/2016-17/07).

\section{Competing interests}

The authors declare that they have no competing interests.

Received: 18 March 2021 Accepted: 11 July 2021

Published online: 28 July 2021

\section{References}

1. Das A, Deka S. Fermented foods and beverages of the north-east india. Int Food Res J. 2012;19(2):377.

2. Bora S, Keot J, Das S, Sarma K, Barooah M. Metagenomics analysis of microbial communities associated with a traditional rice wine starter culture (xaj-pitha) of Assam, india. 3 Biotech. 2016;6(2):153.

3. Das A, Deka S, Miyaji T. Methodology of rice beer preparation and various plant materials used in starter culture preparation by some tribal communities of north-east india: a survey. Int Food Res J. 2012;19(1):101

4. Das A, Khawas P, Miyaji T, Deka S. Hplc and GC-MS analyses of organic acids, carbohydrates, amino acids and volatile aromatic compounds in some varieties of rice beer from northeast india. J Inst Brew. 2014;120(3): 244-52.

5. Lee H-J, Yoon Y-S, Lee S-J. Mechanism of neuroprotection by trehalose: controversy surrounding autophagy induction. Cell Death Dis. 2018;9(7): $1-12$.

6. Deka A, Handique P, Deka D. Antioxidant-activity and physicochemical indices of the rice beer used by the Bodo community in north-east India. J Am Soc Brew Chem. 2018;76(2):112-6.

7. Handique P, Deka A, Deka D. Antioxidant Properties and Phenolic Contents of Traditional Rice-Based Alcoholic Beverages of Assam, India. Nat Acad Sci Lett. 2020;43(6):501-3.

8. Han F, Xu Y. Identification of low molecular weight peptides in chinese rice wine (huang jiu) by UPLC-ESI-MS/MS. J Inst Brew. 2011;117(2):238-50.

9. Bier DM. The energy costs of protein metabolism: lean and mean on Uncle Sam's team. In: The role of protein and amino acids in sustaining and enhancing performance. Institute of medicine (US) committee on military nutrition research. Washington (DC): National Academies Press (US); 1999. p. 109-19. https://doi.org/10.17226/9620.

10. Murakami T, Furuse M. The impact of taurine-and beta-alanine-supplemented diets on behavioral and neurochemical parameters in mice: antidepressant versus anxiolytic-like effects. Amino acids. 2010;39(2):427-34.

11. Hoffman J, Gepner $Y$, Cohen H. $\beta$-Alanine supplementation reduces anxiety and increases neurotrophin expression in both young and older rats. Nutr Res. 2019;62:51-63.

12. Varanoske A, Wells A, Boffey D, Harat I, Frosti C, Kozlowski G, Gepner Y, Hoffman J. Effects of high-dose, short-duration $\beta$-alanine supplementation on cognitive function, mood, and circulating brainderived neurotropic factor (bdnf) in recreationally-active males before simulated military operational stress. J Diet Suppl. 2021;18(2):147-68.

13. Kannan S, Krishnamoorthy G, Palanichamy P, Marudhamuthu M. Role of Gut Microbiome in Neuromodulation. In: Understanding Host-Microbiome Interactions-An Omics Approach. Singapore: Springer; 2017. p. 105-22. https://doi.org/10.1007/978-981-10-5050-3_8.

14. Kim B, Hong V, Yang J, Hyun H, Im J, Hwang J, Yoon S, Kim J. A review of fermented foods with beneficial effects on brain and cognitive function. Prev Nutr Food Sci. 2016;21(4):297.

15. Marco M, Heeney D, Binda S, Cifelli C, Cotter $P$, Foligné B, Gänzle M, Kort R, Pasin G, Pihlanto A, et al. Health benefits of fermented foods: microbiota and beyond. Curr Opin Biotechnol. 2017;44:94-102.

16. van de Wouw M, Walsh A, Crispie F, van Leuven L, Lyte J, Boehme M, Clarke G, Dinan T, Cotter P, Cryan J. Distinct actions of the fermented beverage kefir on host behaviour, immunity and microbiome gut-brain modules in the mouse. Microbiome. 2020;8:1-20.

17. Hashikawa-Hobara N, Mishima S, Nagase S, Morita K, Otsuka A, Hashikawa N. Effects of alcoholic beverage treatment on spatial learning and fear memory in mice. Biosci Biotechnol Biochem. 2018;82(8):1417-24.

18. Khan M, Bhaskar B, Adak A, Talukdar N. Rice based bever-age with high alcohol content and method therefor. Pat Off J India. 2017;11/2017:6850. (Patent Application No. 201731006470).

19. Caputi A, Ueda M, Brown T. Spectrophotometric determination of ethanol in wine. Am J Enol Vitic. 1968;19(3):160-5.

20. Miller $\mathrm{G}$. Use of dinitrosalicylic acid reagent for determination of reducing sugar. Anal Chem. 1959;31(3):426-8.

21. Leong $L$, Shui G. An investigation of antioxidant capacity of fruits in singapore markets. Food Chem. 2002;76(1):69-75.

22. Singleton $V$, Orthofer R, Lamuela-Raventós R. [14] analysis of total phenols and other oxidation substrates and antioxidants by means of folin-ciocalteu reagent. Methods Enzymol. 1999;299:152-78. 
23. Das S, Deb D, Adak A, Khan M. Exploring the microbiota and metabolites of traditional rice beer varieties of Assam and their functionalities. 3 Biotech. 2019;9(5):174.

24. Komada M, Takao K, Miyakawa T. Elevated plus maze for mice. JoVE (J Visualized Exp). 2008;22:1088.

25. Miedel C, Patton J, Miedel A, Miedel E, Levenson J. Assessment of spontaneous alternation, novel object recognition and limb clasping in transgenic mouse models of amyloid $\beta$ and tau neuropathology. JoVE ( $J$ Visualized Exp). 2017;123:55523.

26. Pellow S, Chopin P, File S, Briley M. Validation of open: closed arm entries in an elevated plus-maze as a measure of anxiety in the rat. $J$ Neurosci Methods. 1985;14(3):149-67.

27. Nakagawasai O, Onogi H, Mitazaki S, Sato A, Watanabe K, Saito H, Murai S, Nakaya K, Murakami M, Takahashi E, et al. Behavioral and neurochemical characterization of mice deficient in the n-type Ca2+ channel $\alpha 1$ b subunit. Behav Brain Res. 2010;208(1):224-30.

28. Hatanaka M, Morita H, Aoyagi Y, Sasaki K, Sasaki D, Kondo A, Nakamura T. Effective bifidogenic growth factors cyclo-val-leu and cyclo-val-ile produced by bacillus subtilis c-3102 in the human colonic microbiota model. Sci Rep. 2020;10(1):1-9.

29. Lou H. Dopamine precursors and brain function in phenylalanine hydroxylase deficiency. Acta Paediatrica. 1994;83:86-8.

30. Zhou Y, Danbolt N. Glutamate as a neurotransmitter in the healthy brain. J Neural Transm. 2014;121(8):799-817.

31. Surman C, Vaudreuil C, Boland H, Rhodewalt L, DiSalvo M, Biederman J. L-threonic acid magnesium salt supplementation in adhd: an open-label pilot study. J Diet Suppl. 2021;18(2):119-31.

32. Huang T, Gao D, Hei Y, Zhang X, Chen X, Fei Z. D-allose protects the blood brain barrier through ppar $\gamma$-mediated anti-inflammatory pathway in the mice model of ischemia reperfusion injury. Brain Res. 2016;1642: 478-86.

33. Khalifeh M, Read M, Barreto G, Sahebkar A. Trehalose against Alzheimer's disease: insights into a potential therapy. BioEssays. 2020;42(8):1900195.

34. Xu J, Wu H, Wang Z, Zheng F, Lu X, Li Z, Ren Q. Microbial dynamics and metabolite changes in Chinese rice wine fermentation from sorghum with different tannin content. Sci Rep. 2018;8(1):1-11.

35. Zhang J, Zhu X, Xu R, Gao Q, Wang D, Zhang Y. Isolation and identification of histamine-producing enterobacteriaceae from qu fermentation starter for Chinese rice wine brewing. Int J Food Microbiol. 2018;281:1-9.

36. Martin CR, Mayer EA. Gut-brain axis and behavior. In: Nestle Nutr Inst Workshop Ser, vol 88. Basel; 2017. p. 4554. https://doi.org/10.1159/ 000461732.

37. Cryan J, Dinan T. Mind-altering microorganisms: the impact of the gut microbiota on brain and behaviour. Nat Rev Neurosci. 2012;13(10):701-12

38. Elshaghabee F, Rokana N, Gulhane R, Sharma C, Panwar H. Bacillus as potential probiotics: status, concerns, and future perspectives. Front Microbiol. 2017;8:1490.

39. Kimura K, Yokoyama S. Trends in the application of bacillus in fermented foods. Curr Opin Biotechnol. 2019;56:36-42.

40. Cheng HW, Jiang S, Hu J. Gut-Brain Axis: Probiotic, Bacillus subtilis, Prevents Aggression via the Modification of the Central Serotonergic System. In: Oral Health by Using Probiotic Products. IntechOpen; 2019. https://doi.org/10.5772/intechopen.86775.

41. Dimidi E, Cox S, Rossi M, Whelan K. Fermented foods: definitions and characteristics, impact on the gut microbiota and effects on gastrointestinal health and disease. Nutrients. 2019;11(8):1806.

42. Lee N-K, Lim S-M, Cheon M-J, Paik H-D. Physicochemical analysis of yogurt produced by leuconostoc mesenteroides h40 and its effects on oxidative stress in neuronal cells. Food Sci Anim Resour. 2021;41(2):261.

43. Shah N. Functional cultures and health benefits. Int Dairy J. 2007;17(11): 1262-77.

44. Pusceddu M, Murray K, Gareau M. Targeting the microbiota, from irritable bowel syndrome to mood disorders: focus on probiotics and prebiotics. Curr pathobiology Rep. 2018;6(1):1-13.

45. Sarkar A, Lehto S, Harty S, Dinan T, Cryan J, Burnet P. Psychobiotics and the manipulation of bacteria-gut-brain signals. Trends Neurosci. 2016;39(11):763-81.

46. Zorraquín-Peña I, Esteban-Fernández A, González de Llano D, Bartolomé $\mathrm{B}$, Moreno-Arribas M. Wine-derived phenolic metabolites in the digestive and brain function. Beverages. 2019;5(1):7.
47. Luna R, Foster J. Gut brain axis: diet microbiota interactions and implications for modulation of anxiety and depression. Curr Opin Biotechnol. 2015;32:35-41.

\section{Publisher's Note}

Springer Nature remains neutral with regard to jurisdictional claims in published maps and institutional affiliations.
Ready to submit your research? Choose BMC and benefit from:

- fast, convenient online submission

- thorough peer review by experienced researchers in your field

- rapid publication on acceptance

- support for research data, including large and complex data types

- gold Open Access which fosters wider collaboration and increased citations

- maximum visibility for your research: over $100 \mathrm{M}$ website views per year

At BMC, research is always in progress.

Learn more biomedcentral.com/submissions 